\title{
Design of Real Time Multiprocessor System on Chip
}

\section{V.V.Mane and U.L.Bombale}

Rajarambapu Institute of Technology Rajaramnagar/CSE, Sangli, India

Department of Electronics technology, Shivaji University Kolhapur/ET, Kolhapur, India

\begin{abstract}
Actually, multiprocessor architecture is one of the solutions to fulfill the heavy computational requirements of the new applications running on embedded systems such multimedia and 3D games. The design of such systems pose various problems located at different level: architecture topology, lack of multiprocessor RTOS. Hence, we suggest in this paper a new topology of multiprocessor architecture as well as a generic layer of inter-processor communication which allows the adaptation of the single processor operating systems to multiprocessor architectures.

Finally, we round off this article by a comparison between some possible architecture for the design of a system. Those experiments are made through the 3D images synthesis application.

The full text of the article is not available in the cache. Kindly refer the IJCA digital library at www.ijcaonline.org for the complete article. In case, you face problems while downloading the full-text, please send a mail to editor at editor@ijcaonline.org
\end{abstract}

